\title{
OPERATING ROOM AIR POLLUTION: INFLUENCE OF ANAESTHETIC CIRCUIT, VAPOUR CONCENTRATION, GAS FLOW AND VENTILATION
}

\author{
S. Mehta, W.J. Cole, J. Chari, and K. Lewin
}

THE PRESENCE of trace amounts of anaesthetic agents in ambient operating-room air has recently been reported, while measurable amounts of halothane and methoxyflurane vapour have been detected in end-expired air of anaesthetists and theatre staff (Linde and Bruce, ${ }^{1}$ 1969, Corbett and Ball, ${ }^{2}$ 1971, Whitcher, Cohen and Trudell, ${ }^{3}$ 1971).

Chronic exposure to nitrous oxide is known to cause bone marrow depression (Lassen, et al., ${ }^{4}$ 1956). It has also been suggested that chronic low grade exposure to anaesthetic vapours and gases may be related to an increased spontaneous miscarriage rate and to an increase in the incidence of foetal anomalies (Askrog, ${ }^{5}$ 1970, and Leucz, Nemes and Berta ${ }^{6}$ 1970). From their survey of causes of death in anaesthetists over the period 1947-66, Bruce et al., ${ }^{7}$ (1968) concluded that the incidence of lymphoid and reticuloendothelial malignancy was two to three times greater than expected, amounting to almost 25 per cent of all deaths due to malignant causes. Increases in "Functional disturbances of the Central Nervous System" following prolonged exposure to anaesthetics in poorly ventilated operating rooms have also been cited by Vaisman ${ }^{8}$ ( 1967 ).

Although the causative agents of the effects outlined have not been established, exposure of theatre personnel to atmospheric pollution is undesirable and should be avoided. Attempts have, therefore, been made to reduce the concentration of anaesthetic vapours and gases in the operating theatre, either by means of a suitable anaesthetic gas scavening system or by adsorption to activated charcoal. Since most of the studies on operating theatre pollution have been carried out in the United States of America where the anaesthetic circuits and gas flows employed are different from those commonly used in this country, it was decided to undertake a similar pollution survey by measuring the halothane concentration in the operating-room atmosphere and in end-tidal samples from anaesthetists. The results of these investigations constitute the subject of this paper.

\section{Methods and Materials}

A study was made of the effect of commonly used anaesthetic circuits, gas flows, clinical concentrations of halothane and scavenging systems, on the level of contamination in the ambient atmosphere. Three circuits were compared. These were a Magill semi-closed circuit and a Manley respirator circuit, each with a flow rate of $7 \mathrm{l} / \mathrm{min}$ and a closed circle system with a flow rate of $31 / \mathrm{min}$. The excess expired gases in the case of the circle system were vented through the expiratory valve

From Burnley Group of Hospitals, Burnley, BB10 2PQ, England.

Canad. Anaesth. Soc. J., vol. 22, no. 3, May 1975 
situated near the soda lime cannister. Using the Magill semiclosed circuit and the closed circle system, 1.5 to 2 per cent halothane was administered together with nitrous oxide and oxygen and patients were allowed to breathe spontaneously. Halothane ( 0.5 per cent) was added to the gas mixture when the Manley respirator circuit was in use and respiration was controlled. A Heidbrink expiratory valve was modified by the addition of a collecting manifold to resemble the valve described by Askrog ${ }^{5}$ (1970). This allowed the expired anaesthetic vapours to be released at floor level, or discharged outside through a pipe buried in the floor of the theatre, or adsorbed with activated charcoal. The collecting manifold of the expiratory valve was connected by a flexible breathing tube to $\%$-inch diameter metal pipe buried in the floor which led the anaesthetic vapours outside the theatre. A prototype Cyprane charcoal filter was used. This consisted of a canister filled with $1,200 \mathrm{~g}$ of activated nut charcoal. The weight of carbon occupied virtually all of the cylindrical portion of the canister. The mesh size for the carbon granules was 5-12 mesh. For each experiment a fresh canister was used. Each patient was intubated with a cuffed tracheal tube and the cuff was inflated to obtain an airtight seal in the larynx so that a gas leak around the tube was not responsible for pollution.

Three operating theatres and anaesthetic rooms were used in these studies. Two of the operating theatres studied had capacities of 5,840 and 4,700 cubic feet and were ventilated at flow rates of 940 and 780 cubic feet/minute respectively. This provided a total air exchange every six minutes. The anaesthetic rooms attached to the theatres measured 1,870 and 1,500 cubic feet and the rate of air exchange was similar to that in the theatres. Air inflow was located at the ceiling level and the outlet was near the floor level on an adjacent wall. There was no recirculation of air. The third operating theatre measured 4,455 cubic feet and had no ventilation system.

Atmospheric samples were taken during the middle of the operating session. Twenty $\mathrm{ml}$ of air was drawn slowly, taking approximately 30 seconds, into a clean, gas tight, grease-free glass syringe which was then sealed using a 3-way tap. Air samples from operating rooms were taken approximately five feet above the floor level at recorded distances from the head of the patient, and also at floor level. Only one air sample was taken from each location in each experiment. In the anaesthetic room, air samples were obtained three feet from the anaesthetic machine. End tidal samples were obtained from anaesthetists while they were administering anaesthetics. They were instructed to exhale about two-thirds and then to breathe into a nylon bag which was impermeable to diffusion of halothane. Twenty ml of the expired air was collected in a glass syringe for analysis.

Halothane vapour concentrations were analysed by gas-liquid chromatography, using a Pye Series 104 gas chromatograph equipped with a heated-head flame ionization detector and a gas sample valve (Pye Unicam, Cambridge), fitted with a $0.5 \mathrm{ml}$ sample loop. Analyses were made using a coiled glass column $(275 \mathrm{~cm}$ long and $\times 0.4 \mathrm{~cm}$ i.d.) packed with 15 per cent FFAP (free fatty acid phase; Phase Separations Ltd., Flintshire), coated on acid-washed silanized diatomite "C" 80-100 mesh (Pye Unicam Ltd., Cambridge). The nitrogen carrier gas flow rate was $60 \mathrm{ml} / \mathrm{min}$ and the column was maintained isothermally at $90^{\circ}$. Binary 
gas-vapour samples of oxygen-halothane (produced from a Fluotec vaporiser, Cyprane Ltd., Keighley) were analysed with an interferometer (Carl Zeiss, Jena, G.D.R.), and then used to calibrate the gas chromatograph. Using an amplifier attenuation of $5 \times 10^{4}$, reproducible readings were displayed on the recorder. Air samples containing halothane vapour were subsequently analysed by direct injection into the gas chromatograph via the gas sample loop, using an amplifier attenuation of $20 \times 1$. The attenuation of the amplifier from $5 \times 10^{4}$ to $20 \times 1$, nominally a multiplication factor of 2,500 , was accurately calibrated (Pye Unicam Ltd.) over this range giving a corrected factor of 2,600. The corrected figure was used to calculate the parts per million of halothane present in the air samples. The $0.5 \mathrm{ml}$ loop was exchanged for one of $2 \mathrm{ml}$ capacity for analysis of very low halothane concentrations.

\section{Results}

Table I summarizes data comparing halothane concentrations in ambient air in the unventilated operating theatre and in end-tidal samples from the anaesthetists, while using various anaesthetic circuits, with and without scavening equipment. The highest concentration of halothane (13.6 p.p.m.) was found within a two-foot radius of the head of the patient or in the inhalation zone of the anaesthetist while using the Magill semiclosed circuit. The overall average concentration in the theatre was 11.2 p.p.m. Halothane concentration in end-tidal samples from the anaesthetists appear to follow closely the mean concentration found within a twofoot radius of the head of the patient. The closed circle system was able to reduce the overall average concentration of halothane in the operating room to 3.3 p.p.m. The average concentration of halothane in the theatre with the Manley respirator circuit was 2.7 p.p.m. Releasing anaesthetic vapours at floor level, while using the Magill semiclosed circuit, the average concentration of halothane in the theatre atmosphere was reduced from 11.2 p.p.m. to 8.2 p.p.m. and in end-tidal air from 12.1 p.p.m. to 6.3 p.p.m. The use of similar scavenging equipment with the closed circle system led to a slight increase in both overall concentration of halothane in the theatre atmosphere and in end-expired air of the anaesthetist. Adsorption of halothane vapour by activated charcoal was most effective in reducing the pollution in the theatre; the overall average concentration of halothane in the theatre being 0.8 p.p.m. and 0.6 p.p.m in the end-tidal sample.

Table II displays data comparing halothane concentration in the ventilated theatre atmosphere and in end-tidal air from the anaesthetists, while employing different anaesthetic circuits with and without scavenging equipment. There was a significant reduction in the pollution of theatre environment by halothane vapour, when the theatres were ventilated by supplying air at the rate of ten times the theatre air volume per hour, irrespective of the type of anaesthetic circuit used. With the Magill semiclosed circuit the overall average concentration of halothane in the theatre atmosphere was 2.6 p.p.m. and in end-tidal air 1.8 p.p.m. The closed circle system was capable of further reducing the overall mean ambient halothane concentration to 1.3 p.p.m and the end-tidal halothane to 0.7 p.p.m. Scavenging of anaesthetic vapour outside the operating room led to a reduction of the overall 
MEHTA, et al.: OPERATING ROOM POLLUTION

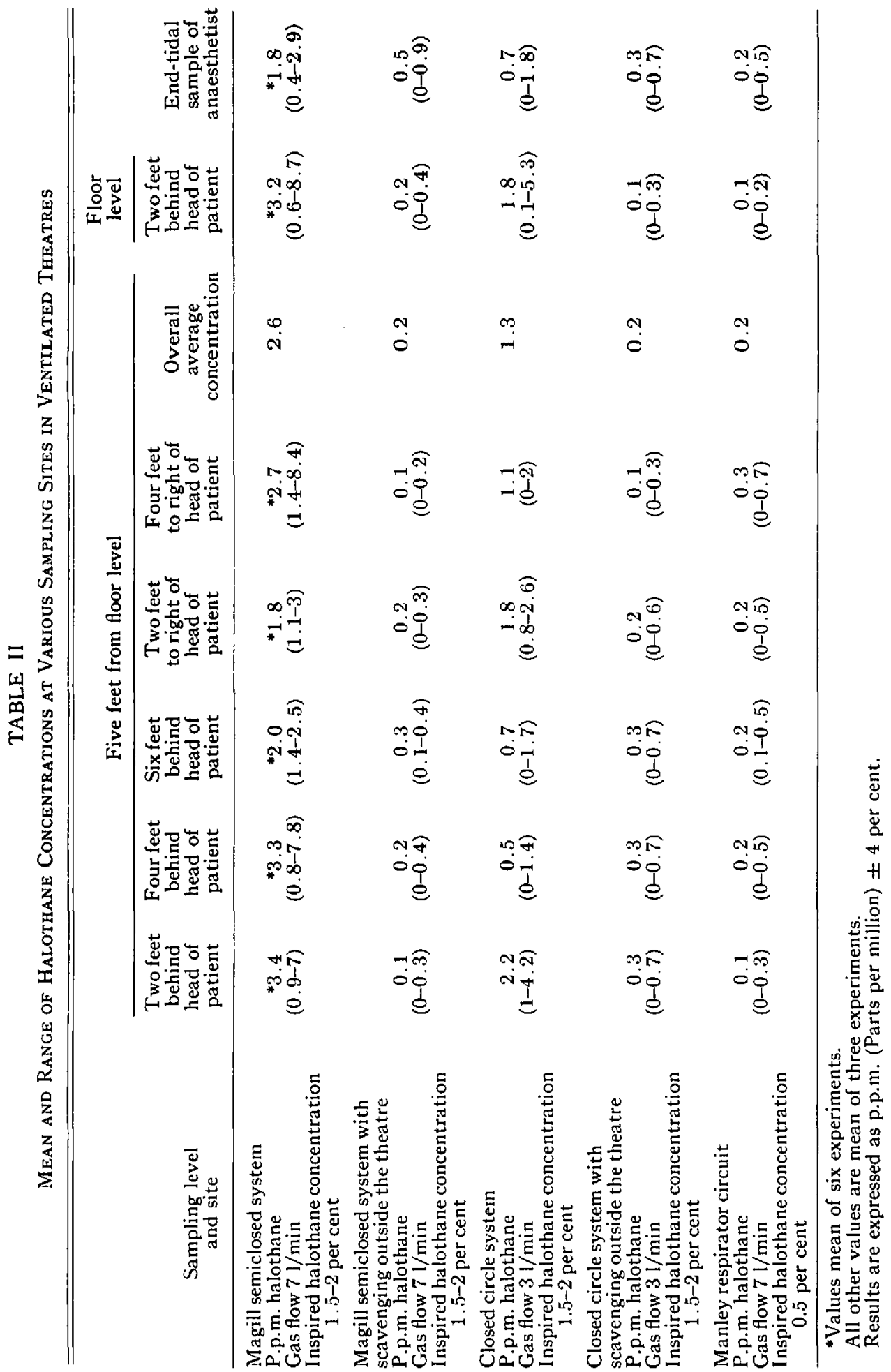


mean concentration of halothane in the operating theatre atmosphere by 92.3 per cent and in end-tidal samples of anaesthetists by 72 per cent with the Magill semiclosed circuit.

Table III shows that halothane levels in air obtained from anaesthetic rooms were considerably lower than those found in the operating rooms and the levels were lower in the ventilated as opposed to non-ventilated anaesthetic rooms.

TABLE III

Ambient Halothane Concentrations in Anaesthetic Rooms

\begin{tabular}{|c|c|c|c|}
\hline \multirow[b]{2}{*}{ Sampling site and level } & \multicolumn{3}{|c|}{$\begin{array}{l}\text { Three feet from anaesthetic machine } \\
\text { and } 5 \text { feet above floor level }\end{array}$} \\
\hline & Mean & Minimum & Maximum \\
\hline $\begin{array}{l}\text { Ventilated rooms } \\
\text { P.p.m. halothane } \\
\text { Magill semiclosed system } \\
\text { Gas flow } 71 / \mathrm{min} \\
\text { Inspired halothane concentration } \\
\quad 1.5-2 \text { per cent }\end{array}$ & 0.4 & 0 & 1.5 \\
\hline $\begin{array}{l}\text { Unventilated room } \\
\text { P.p.m. halothane } \\
\text { Magill semiclosed system } \\
\text { Gas flow } 71 / \text { min } \\
\text { Inspired halothane concentration } \\
\quad 1.5-2 \text { per cent }\end{array}$ & 1.4 & 0 & 4.1 \\
\hline
\end{tabular}

\section{Discussion}

The results of the present study confirm earlier observations of Linde and Bruce ${ }^{1}$ (1969) and Whitcher, Cohen and Trudell ${ }^{3}$ (1971) and indicate pollution of operating theatre environment by anaesthetic vapours. Anaesthetists inhaled higher concentrations of halothane vapour while working in an unventilated operating room, with all three anaesthetic circuits, than did anaesthetists working in ventilated rooms. Generally there appears to be a relationship between overall halothane concentrations in operating room air and end-tidal halothane levels in the anaesthetists. In some instances (Table II) operating room air contained less halothane than the end-tidal air, possibly indicating that the anaesthetist had been exposed to higher concentrations in the recent past. It is obvious from the study that the halothane concentrations are not localized to the anaesthetist but spread over all the theatre at a fairly even level. This suggests that all theatre personnel have an appreciable exposure to halothane similar to that of anaesthetists.

Concentrations of halothane vapour in the theatre atmosphere vary with sampling site, anaesthetic circuit used, total gas flow and vapour concentrations, the scavening system employed to remove expired and excess anaesthetic vapour and efficiency of ventilation. Certain other factors such as the opening of doors, the movement of theatre personnel will cause air currents and result in mixing of the anaesthetic gases and vapours with the room air. Total gas flow and inspired vapour concentration have considerable influence on halothane levels. Whitcher, Cohen and Trudell $^{3}$ (1971), using a nonrebreathing system with a $10 \mathrm{l} / \mathrm{min}$ total 
gas flow rate and 1.0 per cent halothane found the mean concentration of halothane in theatre air to be 8.7 p.p.m. and with a semiclosed system using a flow rate of 4 to $5 \mathrm{l} / \mathrm{min}$ to be 4.93 p.p.m. Their theatres had total air exchange once every six minutes. Corbett and Ball ${ }^{9}$ (1973) determined halothane levels in operating rooms at either 0.5 per cent or 1.0 per cent concentration during administration of anaesthesia using a semi-closed system and a $5 \mathrm{l} / \mathrm{min}$ gas flow rate. Samples collected from the inhalation zone of the anaesthetist ranged from 1 to 2 p.p.m. at 0.5 per cent and 4 to 10 p.p.m at 1.0 per cent Fluotec setting. These authors did not mention the level of ventilation in their theatre. In the present study a significant reduction was found in the overall mean halothane concentration in the ambient atmosphere by using either a closed circle system with a gas flow rate of $31 / \mathrm{min}$ and 1.5 to 2 per cent halothane or a Manley respirator circuit with a $7 \mathrm{l} / \mathrm{min}$ gas flow and 0.5 per cent halothane. Thus one should either avoid open and high flow anaesthetic techniques and encourage the use of a closed circle system with a low gas flow, or use high gas flow only with low halothane concentration.

A ventilation system with a total air exchange rate of 10 times per hour significantly reduced the level of halothane in theatre air, but did not totally eliminate the contaminating vapour. Bruce and Whitcher ${ }^{10}$ (1972) have found that doubling the air exchange rate each hour in the operating room results in only a 50 per cent reduction in ambient concentrations of anaesthetic vapours. Therefore although a high air change rate is desirable, it is not the complete solution to ridding the air of its anaesthetic content.

Perhaps the most effective method of reducing pollution is by the use of appropriately designed scavenging equipment. Whitcher, Cohen and Trudell ${ }^{3}$ (1971) used a 3-litre reservoir bag fitted to an exhalation port and the tail of the bag attached to wall suction. This scavenging system was capable of reducing mean concentrations of halothane in the theatre by 91 per cent with the nonrebreathing circuit and by 85 per cent with the semiclosed circle system. However, with this type of scavenging system there is a danger of applying the extremes of negative pressure direct to the patient's airway. The present authors, with the use of a simple gas venting system, were able to reduce the overall mean concentration of halothane in the operating room atmosphere by 92.3 per cent and in end-tidal samples of anaesthetists by 72 per cent with the Magill semiclosed circuit (Table II). This type of scavenging equipment provides a simple, effective and inexpensive method of dealing with the problem of anaesthetic contamination. It has been clearly shown that the system of releasing halothane vapour at floor level does not significantly reduce the ambient concentration.

However, there are other sources of pollution, such as diffusion through the rubber breathing tubes, leaks from joints in the apparatus, together with the spillage whenever the patient is disconnected from the machine, which always lead to some contamination. This can be overcome by ensuring that the theatre is ventilated by a supply of fresh air at a rate of 20 times the theatre air volume per hour.

Vaughan, Mapleson and Mushin ${ }^{11}$ (1973) and Hawkins ${ }^{12}$ (1973) have described an effective method for removal of anaesthetic vapour by adsorption onto activated charcoal. Using an activated charcoal filter the overall mean concentration of halothane in air was found to be 0.8 p.p.m. (Table I). However Mehta ${ }^{13}$ (1973) pointed 
out that an activated charcoal filter will remove only the vapours of volatile anaesthetics, allowing gases such as nitrous oxide and cyclopropane to pollute the environment.

Whitcher, Cohen and Trudell ${ }^{3}$ (1971) have suggested the practicability of maintaining ambient halothane in the operating room atmosphere below a concentration of 1 p.p.m. In the present study the authors were able, with the help of a simple scavenging system and operating room ventilation with air exchange rate of 10 times per hour, to reduce halothane levels to the order of 0.2 p.p.m. This was achieved irrespective of the type of anaesthetic circuit used and gas flows and vapour concentration employed. Operating theatre ventilation with 20 air changes per hour may be expected to reduce halothane levels below a concentration of 0.2 p.p.m. At the present time toxicity studies of chronic exposure to low concentrations of anaesthetic vapours and gases are limited. It would seem wise, however, to aim at maintaining ambient anaesthetic concentrations in operating room atmosphere at minimum values.

\section{SUMMARY}

Atmospheric halothane was sampled from three selected operating theatres and anaesthetic rooms during the middle of operating sessions. Two of the operating theatres studied were ventilated with total air exchange once every six minutes; the third operating theatre had no ventilation. End-tidal samples were obtained from anaesthetists. Halothane vapour concentrations were analysed by gas-liquid chromatography. The effect of commonly used anaesthetic circuits on the level of contamination in the ambient atmosphere was studied. Concentrations of halothane vapour in the theatre atmosphere were found to vary with sampling site, anaesthetic circuit used, total gas flow and vapour concentration, the scavenging system employed and the efficiency of ventilation system.

Although the ventilation system considerably reduced the level of halothane in the operating room atmosphere, it did not totally eliminate the contaminating vapour. A significant reduction in operating-room pollution was obtained by use of simple scavenging equipment. Scavenging of anaesthetic vapours outside the operating room led to a 97.3 per cent reduction of overall mean concentration of halothane in the operating room atmosphere and reduction of 72 per cent in endtidal samples of anaesthetists, with the Magill semiclosed circuit. The implications of these findings are discussed.

\section{RÉSUMÉ}

La concentration d'Halothane dans l'air ambiant de trois salles d'opération et des salles d'induction attenantes, ont été déterminées au cours d'interventions chirurgicales. Dans deux des salles, un système de ventilation permettait un changement d'air complet aux six minutes; l'autre salle n'avait pas de système de ventilation. On a fait les mêmes analyses dans l'air de fin d'expiration des anesthésistes travaillant 
dans ces salles. On a également étudié les effets de circuits anesthésiques de type courant sur la contamination de l'air ambiant.

Les analyses ont été effectuées par méthode chromatographique. L'on a observé des variations de la concentration d'Halothane dans l'atmosphère des salles d'opération variations en fonction du site de prélèvement de l'échantillon, du genre de circuit anesthésique choisi, du débit de gaz et de la concentration de vapeur utilisés, de l'emploi d'un système de vidange des gaz (scavenging) et de l'efficacité du système de ventilation de la salle.

Le système de ventilation utilisé même s'il diminue considérablement le taux d'Halothane de l'air ambiant, n'éliminait cependant pas de façon complète les vapeurs contaminantes.

L'emploi d'un système simple permettant la vidange des vapeurs anesthésiques à l'extérieur diminuait de façon significative la pollution de l'air de la salle d'opération. De tels systèmes utilisés avec un circuit Magill, permettaient de diminuer de 92.3 pour cent les concentrations d'Halothane dans l'air ambiant de la salle d'opération et de 72 pour cent les niveaux décelés dans l'air de fin d'expiration des anesthésistes.

Les auteurs commentent les implications de ces données.

\section{ACKNOWLEDGMENTS}

We wish to express our thanks to Professor Parkhouse for providing gas chromatographic facilities in the Department of Anaesthetics, University Hospital of South Manchester, Manchester M2O 8LR, and to Mr. I. K. Walker for skilled technical assistance. One of us (W.J.C.) wishes to thank the Medical Research Council for financial assistance.

We are grateful to surgeons, anaesthetists and other theatre personnel at Hartley Hospital, Colne and Victoria Hospital, Burnley, who courteously and willingly co-operated in this study. Our thanks are also due to Cyprane Limited, Keighley, for their generous provision of information and their prototype activated charcoal filter, and to Miss $M$. Jackson for secretarial assistance.

\section{REFERENCES}

1. Linde, H.W. \& Bruce, D.L. Occupational exposure of anaesthetists to halothane, nitrous oxide and radiation. Anesthesiology 30, 363 (1969).

2. ConbetT, T.H., \& BALL, G.L. Chronic exposure to methoxyflurane: a possible occupational hazard to anesthesiologists. Anesthesiology 34, 532 (1971).

3. Whitcher, C.E., Cohen, E.N., \& Trudel., J.R. Chronic exposure to anesthetic gases in the operating room. Anesthesiology 35, 348 (1971).

4. Lassen, H.C.A., Henriksen, E., Neukirch, F., \& Kristensen, H.S. Treatment of tetanus: severe bone marrow depression after prolonged nitrous oxide anaesthesia. Lancet 1,527 (1956).

5. AskroG, V.F. Teratogenic effects of volatile anaesthetics. Abstract, Third European Anesthesiology Conference, Prague, No. 13/01 (1970).

6. Leucz, L., Nemes, C.S., \& Berta, L. Psychische belastungen und morbidit der anaesthetisten. Abstract, Third European Anesthesiology Conference, Prague, No. 63/03 (1970).

7. Bruce, D.L., Eine, K.A., Linde, N.W., \& Eckenhoff, J.E. Causes of death among anesthesiologists: a 20-year survey. Anesthesiology 29, 565 (1968). 
8. VAISMAN, A.J. Working conditions in surgery and their effect on the health of anaesthesiologists. Eksp. Khir. Anesteziol 3, 44 (1967).

9. Conbett, T.H. \& Ball, G.L. Respiratory excretion of halothane after clinical and occupational exposure. Anesthesiology 39, 342 (1973).

10. Bruce, D.L. \& Whitcher, C. Exposure of operating room personnel to anesthetics. A.S.A. Workshop, Boston (1972).

11. Vaughan, R.S., Mushin, W.W., \& Mapleson, W.W. Prevention of pollution of operating theatres with halothane vapours by adsorption with activated charcoal. British Medical Journal 1, 727. (1973).

12. Hawkins, T.J. Atmospheric pollution in operating theatres. Anaesthesia 28, 490 (1973).

13. Menta, S. Anaesthetic contamination. British Medical Journal 2, 241 (1973). 